EPJ Web of Conferences 110,01074 (2016)

DOI: 10.1051/epjconf/201611001074

(C) Owned by the authors, published by EDP Sciences, 2016

\title{
DISPOSAL OF LIQUID COMBUSTIBLE WASTES USING FLAMELESS BURNERS WITH POROUS CARBON MATRIX
}

\author{
Sergei Dolgov ${ }^{1}$ a , Evgenii Savchenko ${ }^{1}$, Sergei Khaustov ${ }^{1}$, Roman Tabakaev ${ }^{1}$ and Alexander Zavorin ${ }^{1}$ \\ ${ }^{1}$ National Research Tomsk Polytechnic University, 634050 Tomsk, Russia
}

\begin{abstract}
Two modifications of flameless burners with a carbon porous media in the combustion area were investigated. Kerosene TS- 1 and mixtures of highly flammable liquids wastes (HIL) were used as fuel. Experimental data are presented in a graphical form as plot of the burner thermal capacity. Results show capacity for of the developed devices and prove the prospects of disposal of liquid combustible wastes using flameless burners with porous carbon matrix.
\end{abstract}

\section{Introduction}

While intensive using of extracted energy resources and accumulation of combustible liquid wastes the questions of its effective incineration as a fuel become significant. However, this resource economy way is limited by insufficiency of scientific knowledge's about burning of such fuels as the accompanying gas, synthesis gas and biogases, gas condensates, waste fuel oil, machine oil, flammable substances, etc., with ensuring the safety of combustion systems operation.

Experience has shown [1-3] that main difficulties are associated with the hydrocarbons quality influenced by the technological combustion systems level. For example, the presence of mineral dash in fine-dispersed phase (sand, rust from piping and vessels, salt deposits) or the presence of the paraffin causes abrasive wear out of the burner structural elements. Resulting sediments in the fuelsupplying channel, spray systems are partially and completely covering its cross section. Such phenomena as uniformity violation in the fuel mixture while its fractional fibration as a result of longterm storage, gasoline leakages in the drainage condensate systems from the pipelines lead to instability, intermittent burning until the flame failure and a high probability of combustible mixture explosion, gaseous fuels burning in case of drainage failures systems accompanied by getting gasoline into the combustion space can lead to a "popping" and the partial destruction of the burner elements [4].

The consequences of these situations are decreasing of inter-repair cycle, reducing of burner lifetime, incomplete combustion and the formation of toxic emission in the combustion products. These factors lead to unplanned shutdowns of the main equipment for the refurbishment and accordingly increase the capital expenditures.

One solution to such problems in a small power can be special burners [5, 6], based on principle of providing fuel mixture treatment and active oxidation inside the porous structure of fractional filler. For example graphite grains of size 2-3 mm (kryptol) can be used as filler in order to form the porous

${ }^{a}$ Corresponding author: sergeydolgov555@rambler.ru

This is an Open Access article distributed under the terms of the Creative Commons Attribution License 4.0, which permits unrestricted use, distribution, and reproduction in any medium, provided the original work is properly cited.

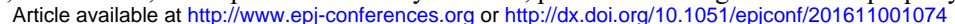


carbon matrix. This principle of preparation of the fuel-air mixture eliminates the possibility of a critical volume for the explosion and helps to prevent flashbacks [7], thereby ensuring the efficiency and security of the burning of both low and high-caloric fuel. A feature of the combustion process inside the carbon filler is to increase the reaction rate of oxidation, while radiation from filler particles provides the fuel preheating. Reaction zones (pores formed with filler particles) size reducing enhances this effect [8].

On the basis of such porous structures heat gasifiers capable of utilizing combustion heat of gases produced by low-temperature catalytic carbon conversion in the filler can be created [9].

\section{The methodology and results of experiments}

To expand the advantages of flameless burners constructional modification for liquid fuels combustion were designed $[5,6]$. Kerosene (brand TS-1) was used as the fuel for the first modification, for the second one a mixture of highly flammable liquids wastes (fuel - HIL) was used. The composition and the thermal characteristics of used fuels are shown in Table 1.

Table 1. Composition and thermal characteristics of fuels.

\begin{tabular}{|c|c|c|c|c|c|c|c|c|c|}
\hline \multirow[t]{2}{*}{ Fuel } & \multicolumn{5}{|c|}{$\begin{array}{l}\text { The elemental composition by weight on a } \\
\text { dry ash-free basis, \% }\end{array}$} & \multirow{2}{*}{$\begin{array}{c}\mathbf{N C V} \\
\left(Q_{r}^{i}\right), \\
\mathbf{k J} / \mathbf{k g}\end{array}$} & \multirow{2}{*}{$\begin{array}{c}\text { Density } \\
(\rho), \mathrm{\kappa g} / \mathbf{M 3}\end{array}$} & \multirow{2}{*}{$\begin{array}{l}\text { Moisture } \\
\left(W^{r}\right), \%\end{array}$} & \multirow{2}{*}{$\begin{array}{c}\begin{array}{c}\text { Ash } \\
\text { content } \\
\left(A^{r}\right), \%\end{array} \\
\end{array}$} \\
\hline & $C^{\text {daf }}$ & $H^{\text {daf }}$ & $N^{\text {daf }}$ & $O^{\text {daf }}$ & $S^{\text {daf }}$ & & & & \\
\hline Kerosene & 83.51 & 16.40 & - & 0.0839 & - & 44835.1 & & & 0.016 \\
\hline HIL & 79.80 & 13.65 & 6.40 & 0.1600 & - & 30236.1 & 884.7 & 0.0002 & 0.120 \\
\hline
\end{tabular}

Field experimental research of burners was performed on a specially designed fire stands (Fig. 1). Features, operation, and test methodology of burners have been described previously [10-13].

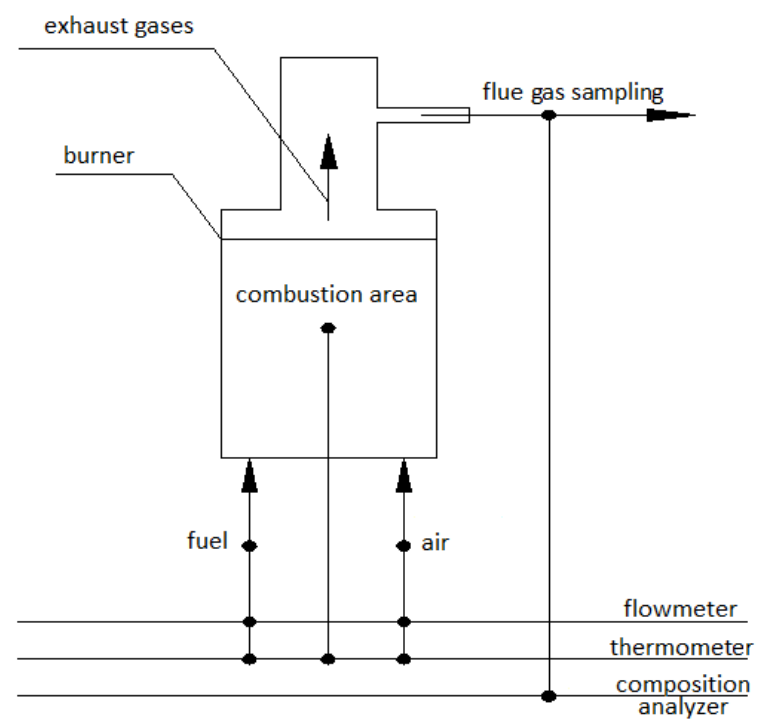

Figure 1. Layout of measuring burner parameters.

The main results of the experiments are presented in a graphical form as plot of the burner thermal capacity (Fig. 2). With increasing the heat load recorded temperatures in the combustion zone varies up to $1300{ }^{\circ} \mathrm{C}$. First modification works in a flameless mode during the entire load range up to a maximum of $6.3 \mathrm{~kW}$. In the second modification flameless combustion of fuel is provided up to $3 \mathrm{~kW}$ of thermal capacity. With further load increasing the process proceeds to the flare mode. 
The results of the burners field tests were used as the input data for the numerical experiment. Simulation of liquid fuels combustion in the porous media was carried out with the engineering software ANSYS Fluent 12.1.4. Design of the computational grid was performed with the ANSYS Workbench software. Gas phase was investigated in the Euler approximation. The standard $k-\varepsilon$ turbulence model with standard wall functions was used. The calculation of radiative heat transfer was performed by the spherical harmonics method $(P 1-$ model $)$.

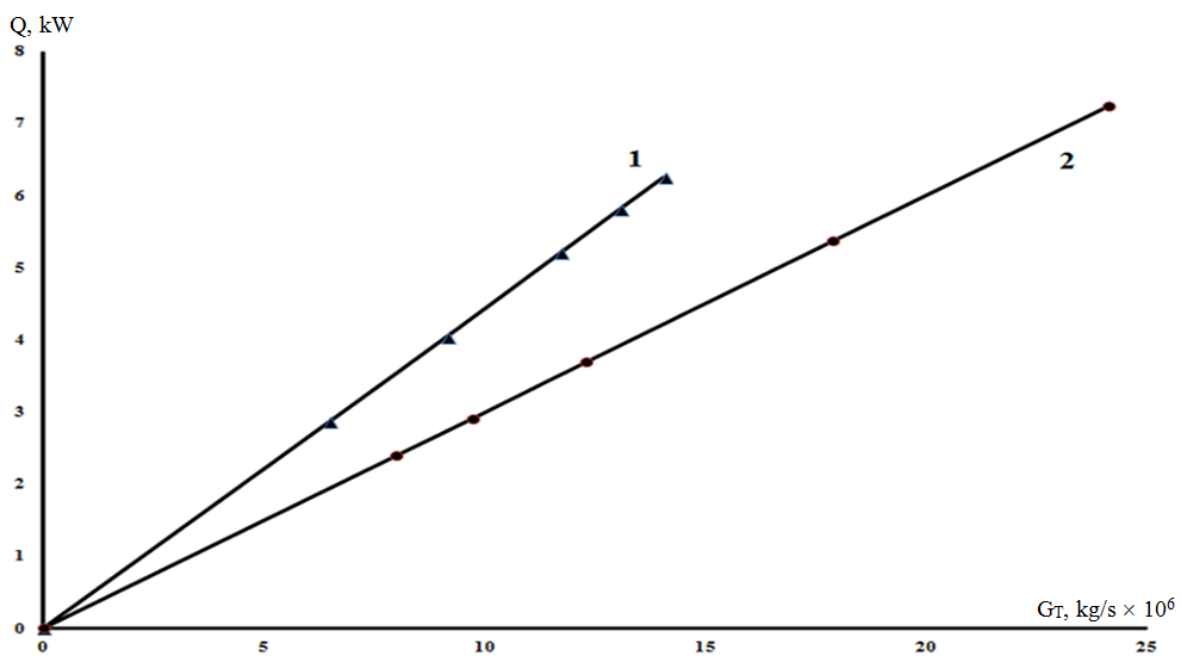

Figure 2. Plot of the burner thermal capacity: 1 - the first modification (fuel - kerosene); 2 - the second modification (fuel - HIL).

Fig. 3 shows graphical visualization of chemical reactions rates of and temperature contours in the combustion area at maximum thermal load.

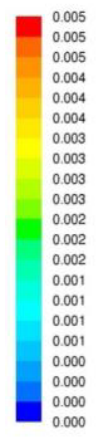

a)

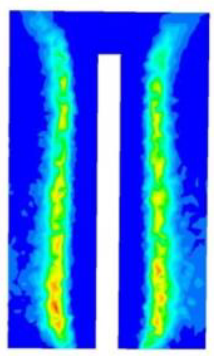

c) b)
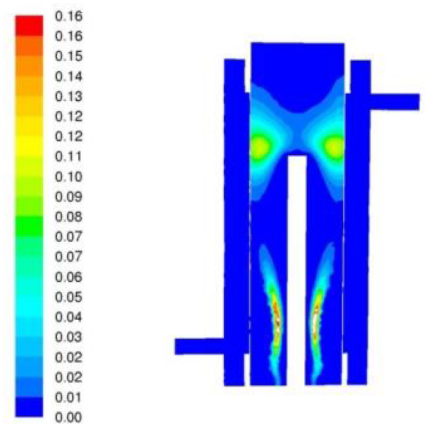

d) 

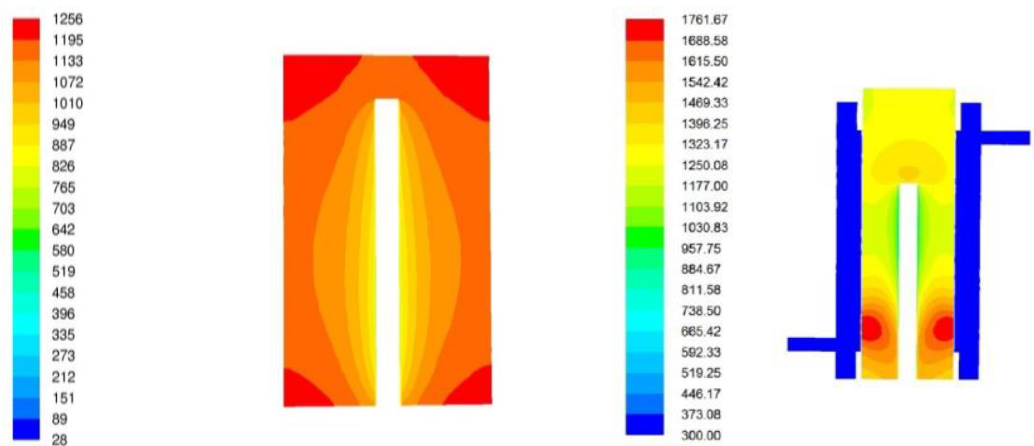

Figure 3. The rate of chemical reaction, $\mathrm{kmol} /\left(\mathrm{m}^{3} \cdot \mathrm{s}\right)(\mathrm{a}, \mathrm{b})$, and temperature fields, ${ }^{\circ} \mathrm{C}(\mathrm{c}, \mathrm{d})$, in the working zone burners: $\mathrm{a}, \mathrm{b}$ - the first modification; $\mathrm{b}, \mathrm{d}-$ the second modification.

The highest values of reaction rate in the porous zone (Fig. 3 a, b) correspond to the spatial localization of mixing stoichiometric conditions, depending on the location, fuel mixture components input distribution, specific for each design modification.

Multi-component content of the HIL mixture results dispersal zones of reaction rate adjustment in porous carbon medium (Fig. $3 \mathrm{~b}$ ). The consequence of this is the possibility of incomplete combustion in the dimensions of the porous filler. It leads to dissemination of combustion in the flame outside the scope of the porous media (Fig. 3 d). On high fuel flow rate values in the process of numerical simulation of the second burner modification using HIL structural conditions conducive to the efficient air distribution inside kryptol filler found were by repeated approximation. Applied to the tested models of the burners 26 orifices more air in the bottom of the working zone are required.

\section{Summary}

The physical and numerical experiments determine the optimum dimensions of the burner elements and carbon porous media filling the working area. Overall, the findings suggest disposal of liquid combustible wastes using flameless burners with porous carbon matrix as the perspective way of useful HIL incineration after appropriate revisions on the identified areas. Achieved results can be used to develop the thermal generation units for mobile autonomous heating systems. Tests with liquid fuel operation confirmed used constructive solutions corresponding the principles and steps of flameless combustion. Designed burner versatility in terms of providing combustion with both flare and flameless modes was detected using the HIL wastes as a fuel.

\section{Acknowledgments}

The reported study was partially supported by the Ministry of education and science of The Russian Federation, state order No. 2069 and No. 13.948.2014/K.

\section{References}

1. P. Gokulakrishnan, M. J. Ramotowski, G. Gaines, C. Fuller, R. Joklik, L. D. Eskin, M. S. Klassen, R. J. Roby, Journal of Engineering for Gas Turbines and Power 130, 051501 (2008)

2. V. I. Yankelevich, Naladka gazomazutnyh promyshlennyh kotel'nyh [Setting up the oil-gas industrial boilers] (Energoatomizdat, Moscow, 1988) [in Russian] 
3. R. A.Visloguzov, R. B. Tabakaev, A. S. Zavorin, S. V. Dolgov, K. I. Klochko, Proc. of 2014 International Conference on Mechanical Engineering, Automation and Control Systems (TPU, Tomsk, Russia), 6986943

4. R. B. Tabakaev, A. V. Astafev, A. V. Kazakov, A. S. Zavorin, MATEC Web of Conferences 23, 01039 (2015)

5. A. V. Talantov, Osnovy teorii gorenija. Ch. 1 [Fundamentals of the combustion theory. Part 1] (KAI AN Tupolev, Kazan, 1975) [in Russian]

6. A. F. Belyaev, B. K. Bobolev, A. I. Korotkov, A. A. Sulimov, S. V. Chuiko, Perehod gorenija kondensirovannyh sistem vo vzryv [Transition of condensed systems burning in explosion] (Nauka, Moscow, 1973) [in Russian]

7. A. S. Zavorin, S. A. Khaustov, N. A. Zaharushkin, IOP Conf. Series: Materials Science and Engineering 66, 012029 (2014)

8. S. A. Khaustov, A. S. Zavorin, K. V. Buvakov, N. A. Zakharushkin, MATEC Web of Conferences 19, 01020 (2014) 